\title{
EDITORIAL
}

\section{The Last Hundred years}

By 1898 the Army Medical Staff, underestablished and underrecruited, had a poor reputation in the eyes both of the civilian profession and of the Army it was attempting to serve. The roots of the matter lay, on the one hand, in absence of military status and on the other, in lack of medical expertise due to limited range of clinical experience and opportunities to update. The department was hidebound and over-regulated with unattractive terms of service. This is not to gainsay the performance of individuals many of whom were distinguished professionally, particularly in Hygiene, Tropical Medicine and Pathology, while many others had been recognised for gallantry.

The Corps formed by the amalgamation of the Army Medical Staff and the Medical Staff Corps was the culmination of extreme public pressure 'to end years of bitter feeling engendered by constant striving against prejudice and evasion'. Within a year of its formation the South African War proved a costly way of demonstrating where the deficiencies lay, and the subsequent Royal Commission gave further support for the new Corps to reform outdated practise in time to meet the challenge of World War.

It has always been necessary to reconcile two disparate professions, medical and military, and the desirable balance between the two is an issue on which a range of opinion exists in the Army at large, and in the civilian profession, as well as in the Corps. No doubt it will continue thus, but it must be accepted that the medical mission is pre-eminent, and the events of the Century have shown that the best way to achieve the mission is through a Corps of the Army in which medical men are responsible for planning and the control of resources, and for the command of medical units and personnel. Only in such a way can medical priorities be given due weight.

The Corps has had to balance two roles-the daily peacetime care of the soldier and the needs of operational support and training and preparation for it. The peacetime role developed into a comprehensive medical service world-wide which cared for soldiers and their families, with evacuation when needed to military reference hospitals in the United Kingdom, and the ever present availability of tertiary referral to honorary civilian consultants who gave freely of their time and expertise. Few in the Army realised how unique a service was available to them. This service provided an environment for vocational training of general practitioners, and within hospitals, allowed to accept the civilian patients to diversify the caseload, nurse and technician training and postgraduate training of hospital specialists. The provision of training itself encouraged high standards and its availability was a major attraction to potential recruits. It also offered job satisfaction further enhanced by changes in terms of service to allow a full career in clinical work without loss of promotion prospects. This was not however just a 'miniature NHS'. It had a specific 'occupational' dimension in that both primary and secondary care had the aim of early response to return the soldier to duty as soon as possible, and was provided by uniformed medical personnel, who lived and served with soldiers and understood their working environment and their needs.

In parallel there has been a need for a cadre of medical officers trained in command and staff duties to organize and lead the Army Medical Services, and to take account of developments in military doctrine to ensure this medical support conforms. This calls for close contact with the General Staff so that advice and development can be pro-active. The link between the specialist disciplines of Aviation, Public
Health and Occupational Medicine and Army staff training created a third career pathway in which both military and specialist medical skills are required.

There has been an understandable tension between the demands of the peace-time service and the need to train for war and provide operational support when needed. While the two activities are in many ways incompatible, they are also interdependant. The concept of cadre field hospitals with nominated reinforcements from peacetime hospitals has worked well and provided a bridge between field and hospital personnel. To remain successful it relies on sufficient regular hospital personnel being available for field duty without undue disruption of the peacetime role, and for field medical personnel to be given sufficient patient contact to maintain clinical skills. Equipment and techniques must be constantly reviewed and updated to achieve best practical working conditions in the adverse field environment.

The turbulence of this Century has meant that operational requirements have fluctuated wildly, and the relatively small size of the regular Corps has called for early reinforcement from the reserves at times of any sizeable operational deployment. Within a year of its foundation the entire regular strength of the RAMC was taken up to provide medical support for the first army corps to be deployed to South Africa and few trained reserves were available. More recently, despite national service, it was necessary to recall reservists for the Suez operation in 1956, and in 1990/91 volunteers from the Territorial Army were called for to complete the medical order of battle to support one division in the Gulf.

The Volunteer Medical Staff Corps was founded in 1883 based on companies of medical students from London teaching hospitals, and was a glorious example of the triumph of amateur enthusiasm over official discouragement. From it the Territorials emerged in 1908 in time to be available as immediate reinforcement in the two World Wars and thereafter. More recently in the latter stages of the Cold War, all TA medical units were given specific war roles in North West Europe with locations identified and equipment stockpiled. This gave a great boost to their training and motivation, and made for a closer relationship with regulars. Nevertheless it is to be hoped that, in the years to come, too much is not asked of these enthusiastic and loyal part-time soldiers to make up for injudicious cuts in the regular Corps.

The first half-century was overshadowed by the World Wars which saw an enormous expansion of the RAMC with the involvement of a large proportion of two generations of the medical profession. The conflicts were catalysts for great advances in medical and surgical techniques, in missile and plastic surgery, in resuscitation and blood transfusion, and in every conceivable refinement of casualty evacuation and of field medical organization. The Corps served with distinction in all theatres of war and received many awards for gallantry while carrying out its responsibilities for the sick and wounded. During those days the whole Nation was involved, the task was clear and the resources needed to do the job had high priority. Nevertheless the task of putting it all together must have been truly formidable and it is an enormous credit to those involved, and a tribute to the leadership of Sir Arthur Keogh in the first War and Sir Alexander Hood in the second, that the Corps was so successful in meeting the demands placed upon it.

The second half-century was more diverse. In the aftermath of the second World War a big Army, consisting to a large degree of national servicemen, was confronted with the need to $\vec{\nabla}$ . . . 怘 (a)

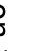
?

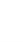

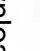

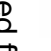
(1) 3.

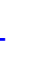

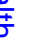

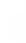

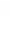

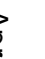
N 
garrison a still widespread Empire and for active service in Palestine, Egypt, Cyprus, Kenya, Malaya, Borneo, Aden and Oman, the Korean War and then the ill-fated Suez Operation; while, at the same time, maintaining a major presence in North West Europe as an essential part of Cold War deterrence. In all these areas the Corps was present, carrying out its twin roles of peace-time care and operational support. It was also called upon to consider a new dimension in warfare and study the medical effects of nuclear and chemical war, and revise priorities of triage in the planning to manage mass casualties.

During this period individuals experienced considerable turbulence. After minimum initial training because of sheer numbers and rapid throughput, they were often moved at short notice to meet medical commitments. It is sad that these circumstances coloured the outlook towards the Army and the Corps of a whole generation of national serviceman who had little motivation towards the military. Nevertheless it is remarkable how many of them seem to value the experience gained, and look back on their time in the Service with understanding and more warmth than they felt at the time.

Since the end of national service a much smaller Army has continued to face new tasks as unpredictable as the Falklands and the Gulf, and as chronic as counter-terrorism in Northern Ireland. Most recently peace-keeping operations have predominated in which the medical mission is central. The sheer diversity of tasks faced by the Corps in its first hundred years is remarkable, as is the rapidity in which circumstances and demands have changed. The challenges have been met with success and distinction through the dedication and selflessness of countless thousands who have served during that time. There have been many acts of valour and notable contributions to medical science, but those who have been recognized and honoured would be the first to acknowledge that their distinction reflects the untold efforts of all who have worn the cap-badge and justified its motto 'In Arduis Fidelis'.

The Corps is now at another significant water-shed, but essentially its twin roles are unchanged. Early response in peacetime care is perhaps even more important in a much smaller Army and immediate readiness to provide operational support remains essential. Medical and military skills have never been higher, but it is important that corporate memory is retained so that the lessons refined from the vast experience gained in this tumultuous Century are passed on. It is also vital that there is sufficient impetus to sustain future development in line with military and medical progress. Above all the Corps must be able to offer worthwhile careers in all its areas of endeavour and not be allowed to fragment through illconsidered reorganization and civilianization. The basis of its foundation was to create an Esprit de Corps which makes every individual in the RAMC a shareholder in its history and, at the same time, responsible to all those who have gone before for its future performance and reputation.

\section{The Millennium and Beyond}

When I was asked to write this look into the Millennium for the Centenary Edition of the Journal of the Royal Army Medical Corps, we were in the middle of the Centenary celebrations and the future seemed clear and bright. This has dimmed somewhat as we reach the close of the celebrations and I regrettably come to the end of my term as Director General. Perhaps I should have requested my successor to undertake the task, but never one to shirk responsibility, I retained the privilege. The Editor suggested I write on the "Next Hundred Years" to balance Major General Tony Shaw's excellent vision of the past. His analysis is perceptive and timely and his final paragraph encapsulates my views for the immediate future. It is what have tried to achieve during my period of stewardship. I a equally aware of the great dangers of long term forecasting and I offer two examples of many I have collected:

"We don't like their sound. Groups of guitars are on the wक्ठ out."

Decca Records rejecting the Beatles 1962

"There is no reason for any individual to have a computer their home:"

Kenneth Olsen Digital Equipment Corporation 1977

The latter statement may in itself be a truism but very from reality. We are, as has been pointed out at a watershêd heading into the 21 st Century. I am conscious that it was years ago that I joined the Corps on a Cadetship, bright eye had difficulty seeing then as far as today. I remember that those were troubled times, which led to the BMA blacklisting a forecasts that we would never recover. But survive we did play a major part in the Deterrence, which led to the demise the Warsaw Pact, in addition to provision of support for tsie conflicts in the Falklands, the Gulf and humanitarian operations in Angola, Bosnia, Croatia, and Rwanda. But the peaee dividend achieved through the many studies, which regrettalgy still continue, has produced a smaller Corps and gaps in capability, the most serious in the hospital based cadre. The remedy to this awaits further pronouncements from the Secretary of State in late December. We have emerge्s enhanced from the Strategic Defence Review, both the Regular and Territorial Army establishments. It has provided framework to move forward with British Army 2000 and the Chief of the General Staff has set out his Vision for the Arigy of the 21 st Century. This very clearly and in detail gives Commanders Intent and will be promulgated down Command Chain. The Army role is expeditionary warfare ag̣d force projection. In order to play our part we must correct ör deficiencies and meet our new targets. We must Recruit, Ret?in and Sustain, which is the Adjutant Generals theme. Seeing evon 15 years into the future remains a difficult forecast, especia as the speed of change increases.

It is recognised that war in 2015 will bear little resemblarise to the 1991 Persian Gulf Campaign. In a new paper, JQ⿱乛龰nt Doctrine for Information Operations, the US Joint Chiefs ָे Staff have inaugurated the next age of warfare, the informat $\frac{\omega}{\mathrm{s}^{n}}$ age. The paper explains the military strategy for computiorbased warfare, including defence against potential strikes 30 n the national infrastructure. This heralds in a new strategic military thinking and will lead to fundamental changes in military operations during war and peacetime deploymeriss. The focus is diffuse including terrorism, cyberwarf biological and chemical weapons, space satellite warfare 商 even natural resource depletion. The battlefield will be a vory different environment and the challenge will be to firg $\mathrm{d}$ technologies that will provide revolutionary capabilitass especially in the information technology area. The medieal technologies are here already in Personal Information Caroier (PIC) devices, Smart cards, LSTAT, Telemedicine and remsiste control operative techniques. Advancement is remarkable in pace and breathtaking in its potential. Budgets must be targeged to "leap-ahead" technologies and our US base liaison offiç্⿸尸 rs monitor this. The Surgeon Generals Telemedicine pro $\overrightarrow{\mathbb{B}} \mathrm{ct}$ shows what pragmatism and limited resources can achieve. To enhance immediate readiness, and military and medical skக్kls the time has come for us to claim our share of the advancegin technology. Simulators have come of age in the medical wo형. 
Apache, Challenger, Rapier simulators train for offence and defence, the resuscitative and anaesthetic trainers in their most sophisticated forms are here now and the cost is minimal compared to these major equipment programmes. These simulators will be essential for combat medical care training in a declining clinical environment and funding must become a matter of priority. The prospects for remote patient care by telemedicine and remote patient case pods currently remain with Star Trek, but I am sure will be developed.

Maintenance and development of the Espirit de Corps with recruitment for the short term has been my aim in this Centenary Year. Sustenance, by the provision of the best training opportunities is the route to medium term improvements. Stability and quality of life must improve, and career advancement must be enhanced. The latter can only be achieved by greater integration with national medical facilities, especially at the highest levels. The recognition we are achieving by demonstrating our expertise to our peer groups is the counterweight to the limited number in society with previous military medical experience. We have become isolated from medical society and are too small to sustain ourselves. Recruiting may be on the turn, and new initiatives, especially where greater recruiting through the Royal Colleges, could $c$ play, a part. We need to make late entry a routine procedure $D$ with continuity training and allow easy transference to and from the Territorial Army. The part played by the volunteer will of necessity expand, but until we provide fast track mobilisation and travel for these key specialists there will be a reluctance on their part for their support to reach its full potential. In this the Government as the employer of the majority who join the medical volunteers, could help by indicating unequivocal support.

Clinical governance will be the latest challenge to medical perception and the achieving of best practice. This has significance for those who are providers, especially those who make provisions for the care of the soldier on the battlefield. The future of military healthcare is one of rapid and major change. Meeting the challenge that is required into the next century will not be easy and we must use technology to enhance the quality of care that we provide, not as a substitute for trained and expert people. The fundamental aim remains to provide the best medical care for the soldier and to train for his support on military operations.

WR SHORT

\section{ACADEMIC ACHIEVEMENTS}

\author{
ChM (Master of Surgery) \\ (University of Manchester)
}

Maj DP Edwards RAMC

\section{HONORARY CONSULTANTS}

Lt Col TJ Hodgetts is appointed Visiting Professor of Emergency Medicine \& Trauma in the European Institute of Health \& Medical Sciences from 1 August 1998 to 31 August 2001. This is an honorary appointment. 